\title{
Pluralismo e consenso: uma tentativa de reconciliação
}

\author{
Pluralism and consensus: an attempt at reconciliation
}

\section{João Kamradt}

Mestrando na Universidade Federal de Santa Catarina (UFSC), Florianópolis, SC, Brasil

joaokamradt@gmail.com
Resumo: O consenso, na maior parte das vezes, é considerado como sendo a maneira ideal para que se garanta a legitimidade política. Mesmo assim, o pluralismo possui muitos argumentos a seu favor e ardorosos defensores. Neste artigo, tentarei conciliar estes dois conceitos que atualmente parecem tão distantes. Para isso, o pluralismo deve ser aceito e valorizado dentro de um nível simples de valores, crenças e preferências. Neste nível, tento demonstrar, o pluralismo pode coexistir com o metaconsenso normativo, epistêmico e de preferência, todos os quais têm qualidades que devem atrair mais pluralistas. No entanto, uma atenção especial deverá ser dada ao conceito de metaconsenso e as condições para sua produção.

Palavras-chave: Pluralismo; Consenso; Metaconsenso.

\begin{abstract}
The consensus, in most cases, is considered to be the ideal way to ensure that political legitimacy. Still, pluralism has many arguments in its favor and ardent supporters. In this article I will try to reconcile these two concepts which now seem so far away. For this, pluralism should be accepted and valued within a single level of values, beliefs and preferences. At this level, I try to demonstrate, pluralism can coexist with Dryzekformulation of normative meta-consensus, epistemic and preferably, all of which are qualities that should attract more pluralistic. However, special attention should be given to the concept of meta-consensus and the conditions for its production.
\end{abstract}

Keywords: Pluralism; Consensus; Meta-consensus. 


\section{Introdução}

Tanto o pluralismo como o consenso são ideais políticos que apontam em direções opostas há muito tempo. Mesmo assim, a reconciliação entre os dois conceitos parece algo desejável, já que nem o pluralismo desenfreado e nem o consenso absoluto possuem muitos defensores. Mas se é desejada, a reconciliação se mostra uma tarefa difícil de se realizar, já que qualquer tipo de solução parece acabar privilegiando algum dos lados. Neste artigo, tentarei enfatizar uma resolução que privilegie os dois argumentos, mesmo que em níveis diferentes. Essa solução vai envolver um pluralismo em um contexto de metaconsenso de valores, crenças e preferências. Independente disso, tanto o seu conteúdo como a forma como o metaconsenso é produzido irá exigir uma análise crítica.

Para alcançar este resultado, irei começar examinando alguns dos mais relevantes defensores contemporâneos do consenso, que estarão entre os democratas deliberativos. Depois disso, olharei com mais atenção para o pluralismo liberal, que tem a celebração da diversidade imediatamente qualificada pelo reconhecimento da necessidade de se administrar esta diversidade - o que, muitas vezes, irá significar um consenso em algum tipo de nível. Será dada uma atenção especial a ideia de John Rawls do consenso sobreposto, que acaba se mostrando insuficiente para dar conta de diversidades mais aprofundadas. Também será dada atenção aos pluralistas mais radicais, da corrente da democracia agonística e radical, que desprezam o consenso deliberativo e celebram diversidades mais ambíguas. No entanto, mesmo estes pluralistas críticos exigem algum tipo de substância destas contribuições para o debate político, o que acaba abrindo a porta para que o metaconsenso, nos termos expostos por John Dryzek, seja discutido. Nesse debate, não encontrei nenhuma solução adequada para resolver a tensão entre pluralismo e consenso. Mas consegui obter alguns indicativos do que seria necessário para se alcançar uma resolução.

\section{Argumentos para 0 consenso}

O consenso é a maneira mais óbvia para que indivíduos que são livres permaneçam desta forma, mesmo que sujeitos a decisões tomadas de forma coletiva. O apelo ao consenso remonta a época de Rousseau. Esse modelo - o consenso - é considerado por muitos teóricos políticos contemporâneos como o padrão ideal para a prática política. Isso é ainda mais forte para os democratas da veia deliberativa. A virada deliberativa na teoria democrática significou que a legitimidade de um regime político passou a ser visto em termos de direito ou capacidade das pessoas de participarem na deliberação do conteúdo deste regime. Alguns democratas deliberativos como Manin (2007) consideram que a deliberação foi apenas um prelúdio para a votação e para a regra da maioria, embora a legitimidade tenha sido construída nos procedimentos de deliberação prévios a votação.

Enquanto isso, outros desprezam a diluição "agregadora" do modelo democrático que a votação parece pertencer e ao invés disso endossam o consenso como uma alternativa, conferindo legitimidade na medida em que são informados e não coagidos. Como Cohen coloca em sua clássica declaração: “[...] os resultados são democraticamente legítimos se e somente se eles puderem ser objeto de acordo de livre e refletido entre iguais [...]" (COHEN, 1997, p. 73) ${ }^{1}$. Assim, os críticos não tiveram dificuldades em identificar a democracia deliberativa como a busca pelo consenso, como Young colocou de forma taxativa: "[...] o objetivo da deliberação é chegar a um consenso [...]" (YOUNG, 2001, p. 122)2. Por sua vez, Habermas (1983) reconhece o pluralismo político, mas mantém o consenso como o ideal a ser alcançado para acordos públicos sobre processos de "duas vias" na democracia deliberativa. Habermas chega a essa conclusão a partir da sua teoria da ação comunicativa, na qual ele tenta aplicar a concepção da teoria do discurso à política contemporânea. Tentando dar praticidade a teoria, Habermas considera que o problema da legitimidade política está ligado ao processo de deliberação coletiva que conta com a participação consciente de todos os cidadãos que poderiam vir a ser afetados pelas tomadas de decisões. Antes disso, se supunha que existia apenas aquela forma para expressar a vontade da maioria em um processo de formação da vontade de todos. A maior noção do problema fez com que Habermas elaborasse o que ficou conhecido como princípio D: "Somente são válidas aquelas normas-ações com as quais todas as pessoas possivelmente afetadas possam concordar como participantes de um discurso racional [...]" (HABERMAS, 1983, p. 116). Esse princípio tinha duas características principais. A primeira é fazer com que haja uma mudança na concepção da maioria e de como as decisões são tomadas, já que ao invés de ser uma tomada de decisão coletiva, passou a ser uma discussão racional sobre pessoas iguais. Ou seja, deixou de ser contagem de votos e passou a ser uma tentativa para alcançar uma posição racional no debate político que satisfaça a todos. O outro princípio alterado é o de preferência. A teoria de Habermas afirma que o discurso que sustenta a política deliberativa precisa

\footnotetext{
${ }^{1}$ No original: "Outcomes are democratically legitimate if and only if they could be the object of free and reasoned agreement among equals".

2 No original: "The goal of deliberation is to arrive at consensus".
} 
[...] ser concebida como uma síndrome que depende de uma rede de processos de barganha regulados de forma justa e de várias formas de argumentação, incluindo discursos pragmáticos, éticos e morais, cada um deles apoiado em diferentes pressupostos e procedimentos comunicativos. (HABERMAS, 1995, s\p).

A teoria de Habermas acaba rejeitando o pressuposto da maioria e de que é possível barganhar sobre decisões que estejam pré-estabelecidas. Assim, Habermas cria um terceiro argumento, no qual quer tornar a esfera pública o local para que identidades culturais distintas e diferentes concepções morais se choquem, gerando procedimentos comunicativos. Isso, para ele, se aproximaria do princípio D e envolveria uma " [...] soberania popular procedimentalizada e um sistema político ligados a redes periféricas de uma esfera pública política [...]" (HABERMAS, 1995, s $\backslash p$ ). Mesmo com seus avanços, Habermas não explica como funcionaria a deliberação pública e nem como funcionaria o sistema político e administrativo. Em Entre Fatos e Normas, ele estabelece para onde sua teoria avança:

[...] nos limites da esfera pública ou ao menos de uma esfera pública liberal, os atores podem adquirir somente influência mas não podem adquirir poder político... A influência pública é transformada em poder administrativo somente depois que ela passa pelos filtros dos procedimentos institucionalizados da formação democrática da opinião e da vontade política e se transforma, por meio dos debates parlamentares, em uma forma legítima de legislação. (HABERMAS, apud AVRITZER, 2000, p. 40).

Com isso, Habermas diz que a opinião pública deve se manter informal. Na interpretação de Leandro Avritzer, Habermas se desobriga de ter que pensar sobre os processos de decisão deliberativa:

Por um lado, ele funda todo o processo de legitimação dos sistemas políticos contemporâneos, na medida em que o poder das estruturas administrativas não é capaz de gerar legitimidade. Por outro, ele não é capaz de produzir arranjos institucionais, porque a sua forma não supõe nada mais que a influência em relação ao sistema político. (AVRITZER, 2000, s\p).

\section{Argumentos do pluralismo liberal}

O pluralismo, por sua vez, também vem sendo amplamente comemorado como um dos pilares da democracia porque caracteriza vários centros de poder, contrapõe o autoritarismo e fornece uma munição básica, porém fundamental para o debate político. Robert Dahl localiza o pluralismo na política de grupos de interesse e o coloca no centro da sua explicação e avaliação da democracia liberal americana. O pluralismo de grupos de interesse é um alvo constante para os democratas deliberativos sintonizados com o consenso. Isso porque a soma politicamente ponderada dos interesses privados de forma tão clara não acrescenta nada ao interesse público.

As justificativas liberais para o pluralismo não estão necessariamente ligadas à política de grupos de interesse. Para John Stuart Mill, desacordos políticos foram fundamentais para o desenvolvimento de indivíduos competentes, pois somente em desacordo esses indivíduos poderiam vir tomar as suas próprias posições. A teoria contemporânea do pluralismo liberal se apoia muito em Berlin. Este, destacou a pluralidade e a incomensurabilidade dos valores básicos. Ele acreditava em uma pluralidade de valores que os homens pudessem vir a procurar. Isso não quer dizer que ele acreditava em uma infinidade de diferentes valores. Berlin afirma que os valores humanos possuem um número finito. Além disso, ele diz que os valores seriam objetivos, logo, a natureza e a busca por eles fazem parte do que significa ser humano. Por fim, todas as pessoas devem possuir alguns valores em comum, já que isso é um dos requisitos que faz com que nós sejamos todos seres de uma mesma espécie. É dessa forma que Berlin afirma que seu pluralismo não é relativista: “[...] os valores múltiplos são objetivos, parte da essência da humanidade em vez de criações arbitrárias das fantasias subjetivas dos homens [...]" (BERLIN, 1998, s\p). Deve-se, portanto, respeitar os sistemas de valores que não são necessariamente hostis uns aos outros. Assim, para Berlin, o inimigo do pluralismo será o que ele chama de monismo. Isso quer dizer, a crença de que deverá haver, em algum momento, uma harmonia entre todas as "verdades". $\mathrm{Na}$ visão do pluralismo de Berlin, é possível que exista o confronto entre valores, mas nenhum destes valores poderá se declarar como o "certo".

A justificativa de Berlin para sua adesão ao pluralismo, que ele considera mais próximo de um ideal realista, é a seguinte:

O pluralismo, com a medida de liberdade "negativa" que traz em si, parece-me um ideal mais humano e mais verdadeiro do que as metas daqueles que a buscam, nas estruturas grandes, disciplinadas e autoritárias, o ideal de autodomínio "positivo" por classes, por povos e pelo conjunto da humanidade. É mais verdadeiro porque, ao menos, reconhece o fato de que as metas humanas são muitas, nem todas comensuráveis, e em perpétua rivalidade entre si. (BERLIN, 1997, p. 196).

Logo, podemos concluir que para Berlim, "liberdade negativa" é propícia para o desenvolvimento da diversidade e para o julgamento através de diferentes 
valores. Já Galston (2002, p. 4) entende que o pluralismo é parte da justificativa básica do liberalismo. Assim, diversidade para Galston é um "valor intrínseco", não um problema a ser superado ou gerido, pois é muito diferente do liberalismo de Rawls.

Argumentos liberais não costumam terminar com uma celebração da diversidade. Isso porque a diversidade levanta a questão de como o conflito deve ser gerido. Galston segue a posição de Berlim, reforçando o julgamento pragmático em contextos particulares. Além da restrição constitucional, Galston (2002, p. 65-78) também destaca as "condições mínimas de ordem pública" e de "presunção ética" na contenção de tendências "centrífugas", para usar sua expressão, do pluralismo.

As condições do diálogo em que a reconciliação de valores concorrentes é feita importa e nas mãos de Galston elas têm um forte tom liberal. Incluem "[...] relações claras e estáveis de propriedade, o Estado de direito e uma autoridade pública com capacidade para fazer cumprir a lei [...]" (GALSTON, 2002, p. 65)', além de "[...] uma economia de mercado devidamente regulamentada, um nível básico de serviços sociais [...]" (GALSTON, 2002, p. 66) ${ }^{4}$. O pluralismo liberal do tipo defendido por Berlin e Galston é em si um compromisso pragmático que faz com que alguns liberais e alguns pluralistas fiquem inquietos. Enquanto isso, alguns liberais desviam do pluralismo: o mais conhecido entre eles é John Rawls. Alguns pluralistas também desviam do liberalismo: particularmente, os agonistas. Agora, vou examinar essas duas abordagens, começando por Rawls.

\section{0 consenso sobreposto de Rawls}

Uma das tentativas para conciliar o pluralismo e o consenso é o consenso sobreposto de Rawls (2000) para instituições básicas da sociedade. Esse argumento enfatiza que uma vez que esta estrutura esteja estabelecida, o pluralismo pode avançar em questões políticas específicas. A teoria de Rawls do consenso sobreposto é introduzida para estabelecer uma ideia de uma sociedade bem-ordenada mais realista e ajustada às condições históricas e sociais das sociedades democráticas, o que inclúi o pluralismo razoável. O consenso sobreposto começa a partir do que ele chama de pluralidade ineliminável de "doutrinas abrangentes" nas sociedades contemporâneas. Estas doutrinas podem ser religiosas, ideológicas ou morais

\footnotetext{
${ }^{3}$ No original: "clear and stable property relations, the rule of law, a public authority with the capacity to enforce the law".

${ }^{4}$ No original: "a suitably regulated market economy, a basic level of social provision".
}

e suas diferenças são incapazes de gerar eliminação (Rawls ordena essas doutrinas em Uma Teoria de Justiça). Como, então, é feito o acordo das partes sobre a estrutura básica da sociedade? Rawls rejeita um modus vivendi como uma solução temporária sensível ao poder relativo das partes envolvidas em diferentes doutrinas e que, com as mudanças no poder, são passíveis de serem desfeitas. Para Rawls, o modus vivendi envolve compromissos que pareçam convenientes para cada lado.

Rawls argumenta que um consenso sobreposto deve ser apoiado por cada doutrina por razões morais, mas "[...] a concepção política de justiça que regula as instituições básicas da sociedade é endossada por cada uma das principais doutrinas, religiosas, filosóficas e morais que devem perdurar em uma sociedade de uma geração para outra [...]" (RAWLS, 2000, p. 58). O consenso sobreposto de Rawls é o que melhor reuni razões de concordância entre diferentes doutrinas. Em um extremo, para que haja consenso sobreposto, essas doutrinas precisam ser capazes de reunir as mesmas razões morais. E essas razões devem ser as mais básicas para cada uma das concepções.

Mas vamos explicar mais detalhadamente a teoria de Rawls. O norte-americano estabelece uma distinção entre as concepções de justiça distinguindo aquelas que admitem uma pluralidade de doutrinas abrangentes razoáveis, cada uma com sua concepção de bem e as concepções de justiça que admitem somente uma concepção de bem. No consenso sobreposto, os cidadãos razoáveis aceitam e entendem a justificação da concepção política em termos de razão pública, ou seja, aceitam as razões e as ideias implícitas na política democrática. Assim, a concepção de justiça expressa melhor a concepção política vinda de cidadãos livres, iguais e autônomos. Essa concepção de justiça atende bem aos interesses dos indivíduos. Em contraposição, no consenso sobreposto, os cidadãos razoáveis aceitam concepções políticas vindas de suas visões abrangentes, ou seja, não públicas (RAWLS, 2000, p. 37). Dessa forma, o consenso sobreposto equaciona dois pontos: a visão política de justiça e a visão abrangente razoável de cada um.

A partir do consenso sobreposto do liberalismo político, as doutrinas, religiosas e não-religiosas, sustentam uma concepção política de justiça, baseada em uma sociedade democrática constitucional. Seus princípios, ideias e padrões satisfazem o critério da reciprocidade (RAWLS, 2000, p. 226). O consenso sobreposto é feito entre doutrinas razoáveis em contraposição às não razoáveis. Sendo a concepção política de justiça o alicerce do consenso, ela é apresentada de forma independente das concepções morais, filosóficas e religiosas. Ela é uma concepção 
política e, como tal, recebe apoio por ser percebida a partir das doutrinas abrangentes e razoáveis. Em uma sociedade bem-ordenada, democrática, regida pela justiça como equidade, uma única doutrina razoável e abrangente não garante a base da unidade social, tampouco oferece o conteúdo da razão pública sobre questões políticas fundamentais. No consenso sobreposto, as doutrinas razoáveis endossam a concepção política, partindo cada uma de seu próprio ponto de vista. Mas por que se busca a resolução de conflitos entre doutrinas abrangentes e razoáveis? Porque, para Rawls, as sociedades necessitam de estabilidade, permitindo a legitimidade das regras, procedimentos e ações sociais. Estabilidade não significa induzir os que rejeitam determinada concepção a aceitá-la ou agir de acordo com ela por meio de sanções efetivas, impondo formas de aceitação. Ao contrário, busca-se na legitimidade política uma base pública de justificação apelando para a razão de cidadãos livres e iguais, considerados razoáveis e racionais.

O consenso sobreposto não pode ser tomado como um mero modus vivendi - situação de acordo apenas aparente, em que são possíveis barganhas. Rawls define o consenso sobreposto em termos de profundidade e extensão, sendo "[...] um instrumento de consensualização entre doutrinas razoáveis [...]" (RAWLS, 2000, p. 134). A profundidade requer que seus princípios e ideias políticas tenham por base uma concepção política de justiça, a qual utilize ideias fundamentais da sociedade e pessoas de acordo com a justiça como equidade. A extensão vai além dos princípios políticos fundadores dos procedimentos democráticos, incluindo os princípios que abarcam a estrutura básica como um todo. Por isso, seus princípios estabelecem certos direitos substantivos como liberdade de consciência e pensamento, além da igualdade equitativa de oportunidades e de princípios que atendam às necessidades essenciais (RAWLS, 2000, p. 211-212).

A ideia do consenso sobreposto pressupõe que as doutrinas abrangentes, da maioria das pessoas, não são inteiramente abrangentes e, assim, possuem espaço para o desenvolvimento e adesão independentemente da concepção política, o que ajuda a criar um consenso. A adesão leva as pessoas a agirem com a intenção evidente de entrar em um acordo de arranjos constitucionais, desde que tenham uma garantia razoável de que as outras pessoas farão o mesmo. À medida que o sucesso da cooperação política se mantém, os cidadãos confiam, cada vez mais, uns nos outros. O consenso sobreposto é a base da justificação pública, pois endossa uma concepção política de justiça, garantindo que questões fundamentais possam ser resolvidas por meio dos valores políticos. “[...] a única unidade social possível é aquela derivada de um consenso sobreposto relativo a uma concepção política de justiça [...]” (RAWLS, 2000, p. 202).

Isso garante o ceticismo que Rawls chama de pluralismo razoável, encontrado, por exemplo, em Chantal Mouffe. Para Rawls um indivíduo "razoável" é definido como alguém comprometido com os princípios liberais básicos (MOUFFE, 1996a, p. 249). Assim, não é surpresa que estes indivíduos endossem uma concepção liberal de justiça no consenso sobreposto que ele propõe. Deixando de lado qualquer conteúdo especificamente liberal do consenso sobreposto e com foco voltado para a sua estrutura formal, o ponto geral é que qualquer consenso sobreposto requer um acordo sobre a prioridade de um conjunto de valores substantivos. Habermas é outro a criticar o consenso sobreposto. Para o autor, não se pode esperar dos cidadãos a disposição de adotar um ponto de vista moral independente das perspectivas das distintas concepções de mundo de cada um.

\section{Pluralismo radical}

Um pluralismo contemporâneo mais radical desconfia dos dispositivos liberais e comunitários utilizados para a conciliação da diferença. Esse pluralismo crítico está associado com os teóricos da democracia agonística, como Connolly (1991), Honig (1993) e da radical, como Mouffe (2000). Pluralistas radicais se assemelham a liberais no entendimento de que é possível experimentar o mundo de inúmeras formas, mas as experiências e as perspectivas dos grupos marginalizados e oprimidos tendem a ser diferente e piores do que dos grupos dominantes. Eles também possuem uma forte suspeita da teoria liberal que parece apoiar uma neutralidade, mas que no geral, costuma beneficiar aqueles que possuem mais recursos. Democratas radicais são hostis ao consenso porque a tomada de decisões consensuais esconde a opressão informal, disfarçada da preocupação de uma política destinada para todos, mas que acaba não permitindo que alguém se coloque contra ela. $\mathrm{O}$ grande alvo destas correntes é a teoria política que implanta o consenso, especialmente a teoria deliberativa e liberal. Young (2001) argumenta que os apelos à unidade e ao bem comum dos teóricos deliberativos sob influência do ideal do consenso sobre as formas adequadas da comunicação política podem ser opressivos. Já Mouffe, falando a partir de uma concepção agonística da democracia, afirma:

Para negar o caráter inerradicável do antagonismo e visando a um consenso racional universal - que é a verdadeira ameaça à democracia. Na verdade, isso pode levar a violência que está sendo reconhecida 
e escondida atrás de apelos à "racionalidade", como é frequentemente o caso no pensamento liberal [...]. (MOUFFE, 1996b, p. 248) $)^{5}$.

Para Mouffe, o pluralismo radical significa: "o fim de uma ideia substantiva da boa vida" (MOUFFE, 1996b, p. 246). Mouffe não quer abolir a comunicação em nome do pluralismo e da diferença. Além do liberalismo, ela também adverte teóricos democráticos da diferença, que fariam uma celebração acrítica da diferença, que implica em "[...] subordinação e devem, portanto, ser desafiados por uma política democrática radical [...]” (MOUFFE, 1996b, p. 247). Mouffe levanta a questão dos termos em que o engajamento proposto pelos teóricos da diferença democrática podem prosseguir. As partes devem, idealmente, aceitar que as posições dos outros são legítimas, embora não como resultado de serem persuadidos por um argumento. Em vez disso, é uma questão de estarem abertos a mudança de posição devido à adoção de um determinado tipo de atitude democrática que acabe convertendo o antagonismo em agonismo, lutando assim, para o engajamento crítico, com os inimigos e se tornando em adversários que são tratados com respeito. Respeito aqui não é apenas tolerância (liberal), mas sim a validação positiva da posição dos outros.

Mouffe quer um pluralismo regulado por um determinado tipo de atitude, ou seja, agonística. Assim, ela não propõe um pluralismo não regulamentado como uma alternativa para o consenso (deliberativo). Este acordo não pode ser apenas algo processual, já que isso acabaria implicando um "vale tudo" em termos de disputa de posições. Partindo de premissas problematizadas por Carl Schmitt, Mouffe reconhece no conflito algo insuperável e não só isso, mas também, fundamental para a sociedade. Sem o conflito, não haveria política. Mouffe defende que a democracia precisa ser vista como uma conquista continuamente inacabada, como uma luta constante e ininterrupta, que sempre pode ser ampliada, mas nunca terminada. Em suas palavras:

Longe de ser o resultado necessário de uma evolução moral da humanidade, a democracia é algo de incerto e improvável e nunca deve ser tida como garantida. É sempre uma conquista frágil, que precisa de ser defendida e aprofundada [...]. (MOUFFE, 1996b, p.17).

Para Mouffe e também para Laclau, com quem ela divide inúmeras obras, o trabalho de uma esquerda deverá ser aprofundar a democracia dentro do

\footnotetext{
${ }^{5}$ No original: "To negate the ineradicable character of antagonism and aim at a universal rational consensus - that is the real threat to democracy. Indeed, this can lead to violence being unrecognized and hidden behind appeals to "rationality," as is often the case in liberal thinking.
}

liberalismo político e conseguir fazê-la crescer rumo ao que caracterizaram e nomearam de democracia plural e radical. Esse projeto dos autores de formatar uma nova democracia está diretamente ligado a lógica do liberalismo, já que em última medida acaba sendo responsável por criar mecanismos que enxerguem o pluralismo de sujeitos, discursos e situações e, assim, criem formas de abertura, que é o objetivo que toda democracia radicalizada propõe. Como argumenta Mouffe, não é, necessariamente, o liberalismo que precisa ser questionado. Seus pressupostos são o de defender a liberdade que os indivíduos possuem para que cada um deles possa vir a ser capaz de realizar seus objetivos. Ela rejeita diferenças que acabem implicando em algum tipo de subordinação. Ideais agonistas exigem julgamentos sobre o que é digno de respeito e o que não é. Connolly (1991), por exemplo, se preocupa com afirmações dogmáticas e negações de identidade que possam servir de combustível para ressentimentos existenciais serem alterados, tornando o agonismo impossível.

Assim, para Mouffe e Connolly, os princípios reguladores para a comunicação democrática não são apenas atitudes ou procedimentos; eles também se referem ao mérito dos tipos de reivindicações que são dignos de serem respeitadas. Mas, ao se retirar do "vale tudo" do relativismo, eles precisam de princípios para regular a essência do que por direito pertence ao debate democrático. Quaisquer que sejam as suas diferenças, todas as escolas de pensamento apresentadas concordam que o pluralismo é uma questão potencialmente problemática, bem como um valor. Todos veem a comunicação através da diferença como uma chave para a resolução (exceto os liberais que seguem Rawls que desejam legislar sobre a estrutura básica para a resolução de diferenças). O saldo disto implicará em um pluralismo nos valores, crenças e preferências no contexto do metaconsenso sobre um ou mais desses três aspectos, embora tanto o conteúdo do metaconsenso e a forma como ele é produzido requerem um exame crítico.

\section{A tipologia do consenso e do metaconsenso}

Primeiro, o consenso deve ser dividido a partir dos processos de trabalho em que os indivíduos chegam às suas preferências políticas. Algumas concepções do consenso avançam em termos de agregação de preferências, de forma que o consenso recebe a conotação de um acordo sobre o que precisa ser feito. No entanto, o consenso igualmente pode se referir aos valores e crenças que ajudam a explicar preferências particulares. Preferências, valores e crenças podem 
ser influenciados tanto por procedimentos de decisão como de contexto político. Tendo como base o que teorizou Elster (1998, p. 100), há três tipos de consenso que podem ser identificados. O primeiro consenso, normativo, refere-se a um acordo em relação aos valores de condução do processo de decisão. O segundo, o consenso epistêmico, refere-se ao aspecto crítico da formação de preferência, um acordo para mapear valores em termos de causa e efeito sobre como as ações específicas. O terceiro modelo, o consenso de preferência, refere-se ao grau de concordância sobre o que deve ser feito. $\mathrm{O}$ consenso universal ocorreria com os acordos em todos os três aspectos - normativo, epistêmico e, consequentemente, de preferência. Cada um destes três tipos de consenso possui uma contrapartida "meta", ou seja, o metaconsenso.

O conceito de metaconsenso é introduzido por John Dryzek. Ele oferece uma alternativa para tratar de questões críticas, tais como confronto de identidades e de princípios morais, da manipulação de processos de decisão e de debates políticos. O metaconsenso, assim como o consenso, também pode três tipos: normativo, onde haveria reconhecimento da legitimidade de diferentes valores; epistêmico, no qual haveria disputa da credibilidade entre crenças; e de preferência, em que um conjunto apropriado de discursos e de identidades seriam por eles geradas. O metaconsenso normativo existe na medida em que não há acordo sobre o reconhecimento da legitimidade de um único valor, embora não se estenda sobre um acordo no qual dois ou mais valores devem receber prioridade sobre uma determinada decisão. $\mathrm{O}$ reconhecimento que define o metaconsenso normativo é facilitado na medida em que os valores em questão não requeiram uma compensação, além de ser coerente com o tipo de reconhecimento que se poderia esperar de condições em que não há obrigação de uniformidade normativa no plano material, apenas o reconhecimento do status "generalizável" das normas, o que pode acabar mostrando diferentes posições políticas (DRYZEK, 1990, p. 17). O metaconsenso normativo difere do consenso sobreposto de Rawls porque seu reconhecimento de valores não depende de terem contrapartes em outras "doutrinas abrangentes". Metaconsenso normativo significa que lados diferentes (e diferentes 'eus') devem acabar concordando que os outros também possuem valores legítimos. Uma das conclusões sobre valores é que, no nível abstrato, existe um alto grau de concordância sobre a legitimidade dos valores básicos. Os indivíduos discordam, posteriormente, principalmente sobre a prioridade relativa de valores e como eles se aplicam em casos particulares.

Por sua vez, o metaconsenso epistêmico é um acordo sobre a credibilidade das crenças em disputa e sobre a sua relevância para as normas que definem o tema em questão. Nesse caso, credibilidade significa que é aceita por outros como razoável para manter a crença em questão. O metaconsenso epistêmico pode acomodar a multiplicidade de perspectivas exigidas por argumentos epistemológicos para a racionalidade política do pluralismo. A complexidade de um fenômeno e a incerteza associada podem impedir a escolha definitiva por causa de explicações diferentes e de outras teorias ou perspectivas.

Já o metaconsenso preferencial é importante porque faz a escolha social menos vulnerável a arbitrariedade, instabilidade e a manipulação. O metaconsenso preferencial consiste em um acordo sobre a natureza das escolhas disputadas através de alternativas e possui dois aspectos. $\mathrm{O}$ primeiro diz respeito às alternativas que são consideradas como aceitáveis. E o segundo aspecto do metaconsenso preferencial diz respeito à validade das diferentes maneiras que as escolhas através das alternativas podem ser estruturadas.

Todos os tipos de metaconsenso estão baseados na capacidade dos atores racionais de reconhecerem as identidades, crenças e preferências opostas em situações de conflito. Esse reconhecimento levaria o conflito para outra dimensão, em que as partes envolvidas pudessem construir um acordo trabalhado ou "working agrément". Mesmo assim, esse conceito também traz riscos, como reduzir e desconsiderar diferenças, além de possibilitar manipulações.

Pensando nos valores de pluralistas liberais, como expostos por Berlin (1997) e Galston (2002), eles devem ser discriminados para que permitam a possibilidade de um metaconsenso normativo, embora nenhum deles utilize esta terminologia que foi implantada por Dryzek e Niemeyer. Explicado os tipos de metaconsenso, fica a pergunta: o respeito pelas pessoas seria um passo necessário para a realização do metaconsenso? Respeito pode se referir não só aos valores, preferências e crenças que os indivíduos possuem, mas também à sua personalidade. Indiscutivelmente o reconhecimento dos outros como membros de uma comunidade deve ser um facilitador do diálogo necessário para gerar o metaconsenso. No entanto, o respeito pelas pessoas pode ser irrelevante quando se trata de gerar esse metaconsenso. Como o exemplo que Dryzek e Niemeyer (2006, p. 646) dão, os cristãos podem “odiar o pecado, mas amar o pecador"; como o pecado é odiado, ele está fora dos limites de qualquer metaconsenso. $\mathrm{O}$ respeito por diferentes integridades morais pode prevenir a violência contra elas, mas resulta em uma recusa em apoiar o engajamento destas morais. E esta não é a forma como o respeito agonístico costuma ser discutido. 


\section{0 metaconsenso pode ser um caminho para a solução?}

O metaconsenso pode ser uma forma de conciliar os ideais opostos do consenso e do pluralismo. Esta reconciliação envolveria o pluralismo normativo, epistêmico e de preferência em seu nível simples, juntamente com o consenso sobre um ou mais desses três aspectos em um nível meta. As virtudes do metaconsenso de Dryzek e Niemeyer não implicam que qualquer metaconsenso seja defensável ou que deve haver um esforço para chegar a acordos com grupos extremistas, como pedófilos ou nazistas. Assim como outros acordos, o metaconsenso também tem sua parcela de exclusões. O primeiro argumento a ser feito a favor desta resolução é que no nível mais simples, o consenso de qualquer um dos três tipos é passível de contestação em qualquer sociedade com algum grau de pluralismo. Agora, em processos em que se existe a mediação de, por exemplo, partes em litígio que sentam para decidir uma disputa com mediação de uma terceira parte neutra, acabam muitas vezes produzindo o que parece ser o consenso preferencial, em um sentido que deve ser cumprido.

Mas esse acordo, muitas vezes, representa apenas o que cada parte pode aceitar. Na verdade, as partes somente entram nesse processo apenas se temem que o resultado irá favorecer o adversário. Então, em uma mediação sobre uma disputa, por exemplo, sobre a liberalização das drogas, o movimento a favor da liberalização pode aceitar um resultado que leve a "liberação do uso para quem possua doença e apresente prescrição médica" caso acreditem que se uma decisão for tomada, a alternativa mais provável será pela proibição total das drogas. Obviamente, o acordo não significa que a liberação parcial das drogas é a escolha do movimento a favor da liberação. O resultado só foi alcançado no nível normativo, epistêmico e de preferência por causa do desacordo entre o movimento a favor da liberação e aqueles que desejam a manutenção da proibição. Assim, a mediação envolve a construção de um metaconsenso normativo entre as partes que, inicialmente, estavam hostis umas as outas. O metaconsenso normativo implica na compreensão recíproca e no reconhecimento da legitimidade dos valores que os outros participantes da disputa política possuem. Como ressaltam os autores:

O metaconsenso normativo exige a promoção da capacidade de diferentes grupos em uma sociedade plural possam coexistirem civilizadamente reconhecendo a política democrática que rege suas vidas. Isso, claro, não interfere que eles continuem buscando formas éticas de ressaltar os valores morais que entendem serem os mais importantes [...]. (DRYZEK;
NIEMEYER, 2006, p. 643) ${ }^{6}$.

O metaconsenso de Dryzek e Niemeyer faz menos exigências sobre as partes do que o consenso e por isso é alcançado com mais frequência, além de ser mais otimista do que Mouffe, ao acreditar que sempre o (meta) consenso será preferível do que o antagonismo. Em particular, o metaconsenso ainda pode estar disponível quando as partes continuam a discordar profundamente sobre o que deve ser feito em uma situação. Mas nem sempre é possível alcançar o metaconsenso. Às vezes, as partes preferem continuar lutando. No entanto, em comparação com o simples consenso há menos exigências das partes de se comprometerem com seus valores de primeira ordem, suas crenças e preferências. A realização do metaconsenso é menos dependente das motivações das partes a procura de um acordo. Mesmo quando o desacordo pode ser resolvido pelo voto, o metaconsenso pode facilitar a resolução. E ao contrário do pluralismo radical, não é uma "força" se sobressaindo momentânea sobre outra, e sim um acordo entre elas.

Neste ponto, chegamos à conclusão preliminar de que os ideais de um consenso e do pluralismo na interação política podem ser conciliados com a ideia de que o consenso pertence à um meta-nível, enquanto o pluralismo pertence ao nível simples. Como afirmam Dryzek e Niemeyer (2006, p. 646), “[...] o metaconsenso reconcilia os argumentos teóricos do pluralismo, de um lado, e do consenso, do outro [...]"' Mesmo assim, eles admitem que esse metaconsenso pode acabar caindo em uma manipulação da opinião pública, através da utilização de argumentos que invocam valores e crenças. Os próprios autores citam que a combinação entre símbolos populares como a liberdade com outros indesejáveis, como o terrorismo, pode gerar uma manipulação do metaconsenso normativo. Eles não aprofundam uma forma de escapar dessa armadilha. A solução dos autores ainda é enfatizar a necessidade de que os pluralistas se adequem ao metaconsenso, como mostra a afirmativa de que todos os "[...] pluralistas, sejam liberais ou críticos devem apelar ao final para algum tipo de metaconsenso para regular o pluralismo. Se assim for, os pluralistas não podem evitar a contemplação das condições em que o metaconsenso é produzido [...]." (DRYZEK; NIEMEYER, 2006, p. 647) ${ }^{8}$.

\footnotetext{
${ }^{6}$ No original: "normative meta-consensus not only promotes the ability of different groups in a plural society to coexist in civility and recognize their joint membership of a democratic polity, but also the likelihood that they will engage in a creative search for outcomes that respect the basic values of all parties, however different these values remain".

${ }^{7}$ No original: "Metaconsensus effectively reconciles theoretical arguments for pluralism on the one hand and consensus on the other".

${ }^{8}$ No original: "pluralists, be they liberal or critical, must in the end appeal to some kind of meta-consensus to regulate pluralismo".
} 
Dialogando com Mouffe (2003, p. 17), o metaconsenso normativo pode ser consistente com a ideia de "justiça como reconhecimento" que ela quer promover. Mouffe admite que "A democracia pluralista demanda um certo consenso [...]". Isso não significa que ela endossaria qualquer tipo de metaconsenso normativo. $\mathrm{O}$ metaconsenso normativo pode ter que ser tratado como provisório e em si contestável. Como Mouffe (2003, p. 17) coloca, as "interpretações conflitantes e diferentes" dos "princípios ético-políticos" significam que "uma democracia pluralista necessita oportunizar o dissenso e instituições através das quais ele possa se manifestar". Mouffe enfatiza a contestabilidade continuada de todos os valores políticos. Dentro do agon proposto por Mouffe, a distinção básica entre o agonismo de "inimigos" e de "adversários" implicaria que estes últimos poderiam ser recebidos dentro do metaconsenso normativo, enquanto os primeiros não.

\section{Conclusão}

Não faz muito sentido ser completamente a favor do pluralismo ou totalmente contra o pluralismo. Da mesma forma, não adianta ser um defensor cego do consenso ou um combatente irresponsável de acordos consensuais. Ao longo do texto, argumentei que esses dois ideais concorrentes - consenso e pluralismo - podem ser conciliados por um pluralismo, desde que em um nível mais simples, como mostra a teoria formulada por Dryzek e Niemeyer. Para isso acontecer, esse pluralismo precisa ser combinado com um metaconsenso normativo de valores, crenças e preferências. No entanto, será necessário dispensar uma atenção especial as condições de produção do metaconsenso. Como os autores afirmam: “[...] o metaconsenso normativo implica em compreensão e reconhecimento recíprocos da legitimidade dos valores sustentados por outros participantes na interação política [...]" (DRYZEK; NIEMEYER, 2006, p. 642)9.

Assim como o pluralismo radical, o metaconsenso normativo envolve o reconhecimento através da diferença e também facilita a busca cooperativa de soluções mutuamente aceitáveis para problemas comuns, respeitando as diferenças de valor que podem permanecer profundas e irreconciliáveis. Em um último esforço para conseguir tornar mais clara a aplicação de sua teoria, os autores propõem formas de definição de qual metaconsenso usar em cada situação:

\footnotetext{
9 No original: "Normative meta-consensus implies reciprocal understanding and recognition of the legitimacy of the values held by other participants in political interaction.
}

- O metaconsenso normativo é urgente em situações que caracterizam profundas diferenças de identidades e compromissos de valor.

- Atenção para os limites do metaconsenso epistêmico é especialmente importante em cenários onde os atores poderosos invocam afirmações empíricas questionáveis em apoio dos seus interesses materiais.

- O metaconsenso de preferência importa mais em situações em que um ou mais atores estão em posição para manipular processos de decisão (DRYZEK; NIEMEYER, 2006, p. 647-648) ${ }^{10}$.

Reconhecer esses benefícios não quer dizer que qualquer metaconsenso deve ser incentivado. Mas reconhecer estes limites significam apenas que é preciso estar atento para a possibilidade de um metaconsenso que evitem exclusões. Como afirmam Dryzek e Niemeyer: "Os resultados são democraticamente legítimos na medida em que eles são estruturados por pessoas livres e fundamentadas em um metaconsenso entre os indivíduos [...]" (DRYZEK; NIEMEYER, 2006, p. 648) ${ }^{11}$.

\section{Referências}

AVRITZER, L. Teoria democrática e deliberação pública. Lua Nova: Revista de Cultura e Política, n. 50, 2000. Disponível em: <http://www.scielo.br/scielo. php?pid=S0102-64452000000200003\&script $=$ sci arttext>. Acesso em: 28 jan. 2015.

BERLIN. I. Quatro ensaios sobre a Liberdade. Brasília: Editora da Universidade de Brasília, 1997.

BERLIN. I. Berlin: meu percurso intelectual. São Paulo: Folha de São Paulo, 1998. Disponível em: <http:// www1.folha.uol.com.br/fsp/mais/fs05079805.htm>. Aceso em: 4 fev. 2015.

COHEN, J. Deliberation and democratic legitimacy. In: BOHMAN, J.; REHG, W. (Org.). Deliberative democracy. Cambridge, EUA: MIT Press, 1997. p. 67-91.

CONNOLLY, W. Identity/difference: democratic negotiations of political paradox. Mineapolis: University of Minnesota Press, 1991.

\footnotetext{
${ }^{10}$ No original: - "Normative meta-consensus is especially urgent in situations featuring deep difference in identities and value commitments. - Attention to the bounds of epistemic meta-consensus is especially important in settings where powerful actors invoke questionable empirical claims in support of their material interests.

- Preference meta-consensus matters most in situations where one or more actors is in a position to manipulate decision processes (through, for example, the range of options on the agenda or the order in which votes are taken)".

${ }^{11}$ No original: "Outcomes are democratically legitimate to the degree they are structured by free and reasoned meta-consensus among individuals subject to them".
} 
DRYZEK, J. S. Discursive democracy: politics, policy and political science. Cambridge, EUA: Cambridge University Press, 1990.

DRYZEK, J. S.; NIEMEYER, S. Reconciling pluralism and consensus as political ideals. American Journal of Political Science, v. 50, n. 3, p. 634-649, 2006. http://dx.doi.org/10.1111/j.1540-5907.2006.0²06.x.

ELSTER, J. Deliberation and Constitution Making. In: ELSTER, J. (Ed.). Deliberative democracy. NewYork: Cambridge University Press, 1998. p. 97-122.

GALSTON, W. A. Liberal pluralism: the implications of value pluralism for political theory and practice. Cambridge, EUA: Cambridge University Press, 2002.

HABERMAS, J. Comentários à ética do discurso. Lisboa: Fundação Gulbenkian, 1983.

HABERMAS, J. Três modelos normativos de democracia. Lua Nova: Revista de Cultura e Política, n. 36, 1995. Disponível em: <http://www.scielo.br/scielo. php?script=sci_arttext\&pid=S0102-64451995000200003 $>$. Acesso em: 1 fev. 2015.

HONIG, B. Political theory and the displacement of politics. Ithaca: Cornell University Press, 1993.
MANIN, B. Legitimidade e deliberação política. In: WERLE, D. L.; MELO, R. S. (Org.). Democracia deliberativa. São Paulo: Editora Singular, Esfera Pública, 2007. p.15-45.

MOUFFE, C. Democracy, Power and 'The Political. In: BENHABIB, S. (Ed). Democracy and difference: contesting the boundaries of the political. Princeton: Princeton University Press, 1996a. p. 245-56.

MOUFFE, C. O regresso do político. Lisboa: Gradiva Publicações, 1996b.

MOUFFE, C. The democratic paradox. London: Verso, 2000.

MOUFFE, C. Democracia, cidadania e a questão do pluralismo. Revista Política e Sociedade, n. 3, p. 11-26, 2003.

RAWLS, J. O liberalismo politico. São Paulo: Ática, 2000. YOUNG, I. M. Comunicação e o outro: além da democracia deliberativa. In: SOUZA, J. (Org.). Democracia hoje: novos desafios para a teoria democrática contemporânea. Brasília: Editora Universidade de Brasília, 2001. 